\title{
Performing the Border as a Zone of Contestations: A Critical Analysis of Root Map ${ }^{1}$
}

\author{
Elaigwu Ameh \\ Department of Performing and Media Arts, Cornell University, 430 College Avenue, Ithaca, NY 14850
}

\begin{abstract}
The plethora of meanings associated with the term "border" not only accentuates the frequent use of the word, but also implicates the border as a zone of contestations. These contestations underscore how borders covertly or overtly continue to affect the lives of millions of people across the globe. By "zone of contestations," I situate the border as both a tangible and an intangible site that is replete with competing narratives about migration and migrants themselves. As a zone of contestations, the border eschews the idea of a monolithic story of migration; instead, it presents us with layers of stories by relocating border discourses to the realm of both the personal and the interpersonal lives of those interfacing with the border.
\end{abstract}

Keywords: migration, performance, theatre, border, migrants, deontology, consequentialism

DOI: $10.7176 /$ RHSS/9-24-10

Publication date: December $31^{\text {st }} 2019$

\section{Introduction}

In recent years migration, again, has become one of the most controversial and emotive social and economic issues. This despite its being as old as human beings who moved around to improve their living conditions, for safety and even adventure! In previous phases of globalization and since the eighteenth century, the development of the rich 'North' depended on the movement of millions of people through slavery, indenture and wage labour. The current phase of globalization is little changed; modern migratory movement can best be understood in the context of a globalized market economy that directs the flows of goods, money and labour within and beyond nations. People, however, have much less freedom to move than the goods that they produce and the profit and financial wealth that they create... Yet this simple fact is often ignored in the debate on migration and reveals itself in: 'we asked for labour but then people came. ${ }^{2}$

In the spirit of Mahmood Messkoub's aforementioned quotation, I understand Root Map as a compelling collaborative play that not only crystallizes some of humanity's multifaceted stories of migration into an embodied enactment, but also challenges the actors and spectators to undergo an honest introspective inquisition in an age of unprecedented forced displacement where the othering of migrants appears to be the norm. In a world where migrants are constantly reduced to mere statistics, touted as terrorists, and despised like STDs, this play is not only timely but also necessary as a social change captain to steer the wobbling ship of humanity away from the storms of bigotry which unremittingly pit humans against each other over border crossings.

Appropriately, Linda B. Glaser in Cornell Chronicle calls Root Map "a play about the shared experiences of people encountering borders." On its part, the Multicultural Resources Center did not just call Root Map a "7,837 mile collaboration" between artists based in Kolkata, India and Cornell University, Ithaca, but also added that the play is "a living art piece, meaning that as it travels to a new performance location, the themes explored embody issues and individuals who become involved in that new location." While acknowledging the above descriptions of Root Map as plausible and laudable, my intention in this paper is rather geared towards teasing out and underscoring thematic metanarratives of the play, with a view to engendering an understanding of Root Map as a performance which showcases the border as a zone of contestations. Therefore, even though I participated as an actor in four performances of the play, this paper does not seek to give a back story or an insider view of the rehearsals or the entire production process. It also does not purport to serve as a barometer for gauging the affective fever and nostalgia the play generated in spectators in the different locations where it was staged, even though any of these angles too would make for a fascinating paper. With these notes, to the intent of this paper I now turn.

Over the years, people in various climes have used the term "border" to refer to a multitude of realities. The plethora of meanings associated with the term not only accentuates the frequent use of the word, but also implicates the border as a zone of contestations. These contestations underscore how borders covertly or overtly continue to affect the lives of millions of people across the globe. By "zone of contestations," I situate the border as both a tangible and an intangible site that is replete with competing narratives about migration and migrants themselves.

${ }^{1}$ Root Map is a living play about visceral border experiences of migrants. Its principal creative team include Prof. Debra Castillo, Carolina Osorio Gil, Rosalie Purvis and Elaigwu Ameh - all members of Cornell University, as well as Debasish Sen Sharma and Debaroti Chakraborty, who are Kolkata-based artists. This creative team is a community of scholars and artists from diverse cultural heritages across Africa, Asia, Europe, North America and South America. The play had its inaugural performance on January 27, 2017 in Kolkata, followed by performances on March 2, 2017 in Ithaca; March 4, 2017 in El Paso, Texas; and August 26, 2017 in Akwesasne.

${ }^{2}$ Messkoub, M., 2009. "Migration in a Globalizing World.” Development Issues. 11(2), p.2. 
As a zone of contestations, the border eschews the idea of a monolithic story of migration; instead, it presents us with layers of stories by relocating border discourses to the realm of both the personal and the interpersonal lives of those interfacing with the border. As a play about border experiences, Root Map, I contend, evidences the following contestations: (a) universalism versus particularism; (b) deontology versus consequentialism; (c) objectification of humanity versus assertion of subjectivity; and (d) the physical versus the intangible dimensions of the border.

\section{The Border as a Zone of Contestations}

One of the border contestations in Root Map demonstrates both the universality and the particularity of border experiences. Contrary to dominant narratives that seek to conceptualize and memorialize migration as primarily a sectional, religious, or racial debacle, or even as essentially the problem of the underdeveloped world or failed states, Root Map presents migration as indeed a global problem - a human problem. The play opens with migrants of different ages, nationalities, gender and races stumbling onto the stage, all of them saddled with a consignment of fatigue, but kept ebullient by an unwavering hope for a better life across the border. Their manifold diversity echoes the incontrovertible story of migration as a universal, albeit disproportionate, reality in our world todaya reality Messkoub crisply captures in the quote introducing this paper. A reality that draws attention not only to the family tree of lopsided immigrant experiences in a globalized economy, but also to the shared humanity between migrants and their host or destination communities - that shared sense of being that spans different shades of the human community. An understanding of this shared identity is pertinent for the mental housecleaning required for purging deep-seated prejudices proliferating anti-migrant sentiments and charades across the globe.

This momentous motif of universality runs through the play and attains prominence once more through the performance's accretion of multiple languages, including English, Hindi, Spanish, Pidgin, Portuguese, Idoma, Bangla, French and Dutch. Though embodying different linguistic and ethnic identities, these migrants jointly face the apprehension and discomfiture of border crossings. No doubt, the universality of migration remains a force to be reckoned with in the world today. As Migrant Carolina rightly mentions in the play text, "conflict and violence have forcibly displaced 60 million people worldwide, over 38 million of whom are internally displaced, and 19 million refugees" (5). Likewise, as shown in Glaser's interview with the play's cast members, their personal border experiences equally buttress the point that the border is a global issue as opposed to it being the problem of a section of the globe:

The stories are deeply personal. Purvis is the granddaughter of Holocaust survivors and grew up partly in the Netherlands; her extended family now includes indigenous Africans and Asians. Carolina Osorio Gil, Latina/o studies engagement coordinator and director of the ¡CULTURA! Ithaca program, came to the U.S. from Colombia when she was 4, crossing the U.S.-Mexico border illegally (she is now a citizen). For Indian collaborators Debaroti Chakraborty and Debasish Sen Sharma, the Bangladesh border is a short car drive away ("International Collaboration").

Even though migration has been a universal issue, many people have experienced it differently; thus, any attempt to gloss over the particularities of individuals' experience of migration or the border inevitably excludes a richly diverse repository of border experiences. Root Map recognizes the particularities of the border reality, and proactively employs several scenes and characters to refute a portrayal of the border experience as monolithic. For instance, as Migrant Micky highlights in the play, "[t]he truth is we are all crossing borders. In a search. We all are crossing borders with a story", yet "[t]he truth is we all have our stories to tell" (8). So, even though all the migrants have a shared humanity, their humanity gets impacted in different ways at the border. Similarly, even though they all have at least a story of migration, their individual stories are not uniform: they are an amalgam of various life histories, experiences and border bio-politics.

Little wonder, therefore, for Root Map to emphasize that the border is certainly not peculiar to the existential reality of a homogenous group of people. In other words, it is not only Muslims, for instance, that cross the border into Europe from the Middle East, just as it is not only Mexicans that cross the Mexican border into the United States. Still on the need to recognize the particularities of migrants and immigrants, Root Map reminds us that " $[\mathrm{t}]$ here are almost 1 million lesbian, gay, bisexual, and transgender, or LGBT adult immigrants in the United States today" and that "undocumented immigrants comprise a disproportionately large percentage of the labor force" in the United States (6). Such a reminder enables us not only to recognize the particularities of the immigrant pool, but also to appreciate their significant contribution to their host country's social and economic cartographies.

Another significant contestation in Root Map reveals itself in the philosophical paradigms of deontology and consequentialism. Simply put, the consequentialist view holds that the moral rightness of an act hinges on only the consequences of that act or the motive behind it (Bayles 1968; Mulgan 2001 and Darwall 2003). On the other hand, deontologists demand that we ignore the consequences of one's action. They essentially subscribe to the normative theory that moral choices are not to be judged as right or wrong based on their effects, but according to their conformity to norms or duty (Scheffler 1982; Brook 2007; and Moore 2008). In view of these two aforementioned competing moral theories, I maintain that the two guards in the play are torn between (1) a strict 
adherence to their duty as border patrol officers and (2) their awareness of the consequences of their (in)action on both their country and the hopeful immigrants. Hence, at the subliminal level, the play allows the forces of deontology and consequentialism to vie for influence in the characters of the guards. At first glance, in order to keep away miscreants and terrorists from their country, the guards perform their call to duty religiously, even to the point of not only embarrassing the migrants, but also seemingly stripping them of what is left of their dignity. Through a slew of insults and harassments, culminating in a bacchanalia of demeaning border performances, the guards exert their control over the bodies of the migrants - all under the guise of doing their duty.

But on the flipside, the subtext of the play leaves one wondering about the inner struggles of the guards as they discharge their duties. One wonders what could have become of the guards if they had chosen to neglect their duty and allow migrants "flood" into the country. Were the guards also thinking about the consequences of their action not just on national security, but also on their career and livelihoods? Would they be able to keep their jobs if they chose to abdicate their duty? What would be the consequence of a job loss on the guards and their dependents? If, as a result of their negligence, a terrorist snuck into the country and wreaked havoc on lives and properties, what would become the guards' lot in the court of law or public opinion? These are some of the questions that permeate the subtext of the play, and further complicate an analysis of the characters of the guards and their allegiance to either the deontological or the consequentialist school of thought. The guards may, in fact, be driven by both a sense of duty and an awareness of the consequences of their action or inaction on their society and themselves. Ironically, towards the end of the play when both guards tear down the border wall in search of contrabands, they are confronted with the consequences of their unintentional action - their inadvertent destruction of the border wall. This further demonstrates that, in the zone of border experiences, acts of participating agents (including government, guards and migrants) can lead to unintended consequences. Hence, rather than focusing on only the angle of duty in discourses on border, we need to also pay attention to the competing reality of the consequences of one's actions, including the unintended ones.

A third contestation the border evokes in Root Map pits the objectification of humanity against the assertion of one's subjectivity. In the play, just as in real life, we see border agents and coyotes treat migrants as mere objects in the interstices of their encounters across borders. Stripped of 'personhood,' migrants become reduced to artefacts for exploitation or hapless objects in a circus of humiliation. In Root Map, Coyote's refusal to take Itzel across the border, even after she has paid him with a golden feather evidences the exploitation of migrants during border crossings. Coyote hinges his refusal to take Itzel across the border on the disappearance of the golden feather from his pocket. He proceeds to accuse Itzel of stealing it. This scene personifies the blatant extortion besetting migrants in their encounter with smugglers at the border. Rather than accept responsibility for losing the feather, Coyote passes the blame to Itzel, accusing her: "You took it. You are a thief" (12). Itzel's fervent assertion of innocence could not change Coyote's mind, instead he shoves her plea back down her throat with this blatant response: "I don't have it because you took it" (12). On the other side of the border, Coyote soon learns that Itzel was right and that Abuelita was the one that had stolen the feather, but the harm had already been done: they had already left Itzel behind.

Another evidence of the objectification of humanity appears when the guards ridicule a migrant, Davanama, with one of them asking her "What do I call you? Bird?" (17). Yet another instance is the cow scene where the guards bombard a migrant with a torrent of abusive questions such as: "Are you a terrorist?" "Are you planning to kill the president?" and "What is your name stupid, idiotic fool?" (22). The constant reference to the migrant as a "stupid cow" and the migrant's bodily representation as a cow in the scene further consolidate not just the maltreatment of migrants at the border, but also their reduction to mere objects in the capricious grip of 'omnipotent' overzealous border agents.

Refusing to cower in the face of humiliation, the cow engages in a performative chant to the amazement of the guards. The singular act of chanting signifies migrants' assertion of subjectivity. It represents an emancipatory exertion of migrants' agency in a dominant hegemonic space, irrespective of the undesirable consequences that may follow such an act of transgression. Her assertive melodious chant upsets the power differential between the guards and her and gives her the impetus to exert her agency as a subject. Fittingly, the assertion of her subjectivity elicited applause from fellow migrants and even members of the audience wherever we performed the play.

Indeed, Root Map reminds us of migrants' quest for the good life across the border both for themselves and for their families. In this quest, many migrants do not only endure acts of denigration, but also lend themselves to exploitation in the grip of daredevil egoists and capitalists. The capitalist exploitation, I must note, does not happen only to migrants, but also to people living in towns bordering rich nations. The film Backyard highlights this capitalist exploitation. It depicts young girls in a Mexican border town working submissively in a large factory for a pay that is far less than what their counterparts in the United States would make. And yet they are happy doing it because it pays their bills - or perhaps because they do not have the collective power to negotiate for a better pay. An explicit example of the objectification of humanity in the film remains how teenage girls get kidnapped, molested, murdered, frozen and sold for the depravity and financial aggrandizement of cartels. These girls' lives do not matter to the cartels. They perceive and treat the girls only as objects to assuage the lecherousness of perverts 
in the society. However, the female police officer's bold rescue of a teenage girl from the clutch of a cartel kingpin at the end of the film and the officer's eventual killing of the kingpin demonstrate the constant struggle to accentuate the subjectivity of human persons in the face of an objectifying marauding beast.

Similarly, the competing views of the border as a physical construct and as an intangible reality complicate the border as a zone of contestations. Instinctually, when many people hear the term "border" what comes to mind is a fence, a wall or a physical barrier. But, even as a physical site, the border is not a static location. As depicted in Char, the No-Man's Land, a portion of the border between India and Bangladesh keeps on shrinking as a result of the adverse effects of flooding. This shrinkage complicates the lives of the inhabitants of border villages, further vexing their land-intertwined livelihoods and subjecting them to frequent knotty border crossings in search of means of survival.

But then, as Root Map shows us, the border is not just a physical barrier. It is also not just a physical location. It has intangible dimensions to it too, such as the psychological and emotional burdens which immigrants face at the interstices of their interactions with the dominant culture. As Root Map establishes, migrants do not only cross borders (in the physical sense), borders also cross them (in the non-physical sense). The metaphor of the border crossing them represents how the migrant characters in the play endure multifaceted unpleasant border experiences, including mental abuse, in their expedition to reach the Promised Land. The metaphor of border also captures how migration transgresses the identities, dreams and realities of migrants as they interact with border security.

For many migrants, the beatific vision of a utopian future across the border quickly diffuses and metamorphoses into a dystopia of regrets and fractured hopes at the border or even across the border. For instance, while Itzel's hope of life across the border suffers a premature death in the hands of Coyote at the border, the artistic hope of The Artist and The Little Girl gains resurgence as a consequence of the crumbling of the wall at the end of the play. With the physical border now gone, the migrants in the play glory in the promise of a better life in the new world - a world which nevertheless has series of non-physical borders lined up for them to conquer in order to stand a chance of fulfilling their dreams. A case in point is Khan in the film My Name is Khan. His immigrant status, complicated by his physical appearance, name and religion, brings untold hardship to him at the emotional and psychological levels, culminating in his wife's separation from him and his bold quest to meet the President of the United States in a bid to safeguard his marriage as well as reconstruct the dominant narratives in the post-911 US which indiscriminately parades Muslims as terrorists.

Kahn's experience mirrors the othering experience of migrants in Root Map as well as many migrants around the world. As a result of othering, many (im)migrants feel like a problem in their interactions with border agents or the dominant culture. As José E. Muñoz pinpoints, "feeling like a problem is about feeling apart, feeling separate" (441). This feeling of separateness constitutes one of the non-physical borders that immigrants must overcome in their quest for meaning and acceptance in their new communities. The struggle for acceptance is never an easy task since one must grapple with the impostor syndrome and the constant hegemonic gaze of the dominant culture, which often breeds self-reflexive glance in (im)migrants. This self-reflexivity echoes W.E.B. Du Bois' elucidation of double-consciousness as "a peculiar sensation, this double-consciousness, this sense of always looking at one's self through the eyes of others, of measuring one's soul by the tape of a world that looks on in amused contempt and pity" (1-2). This double consciousness heightens the anxiety nestled within the psyche and bodies of immigrants in their interaction with the dominant culture, thereby forcing them to labour for acceptance at almost every turn in their host communities.

Just like Du Bois and Muñoz, Lorgia García-Peña in The Borders of Dominicanidad also acknowledges the reality of intangible borders when she talks about "the unequal dynamics through which racialized immigrant and ethnic minority subjects are marked as perpetual others" (2). This perpetuation of the otherness narrative makes the bodies of migrants and immigrants a constant battlefield for competing ideologies and value systems. Apart from leaving migrants and immigrants in a state of unrelenting estrangement, it also frustrates their lives, leading to dystopia or mental breakdown in some of them.

\section{Conclusion}

Apart from denouncing the fossilization of migrants into a dominant border narrative of harm and parasitism, Root Map accentuates that borders on their own are not inherently evil; it is what humans do with them that determines their effects on our lives. The play also underscores that borders encompass not only objects in the physical realm, but also incorporeal instruments such as language, ethnicity, gender, class, race and religion. As a living theatrical piece that keeps adapting to the contexts in which it is performed, the incorporeal dimension of Root Map emerges each time it gets staged in a new cultural context. Such is the dynamism underpinning the play-a dynamism that stresses both the globality and liveness of migration; thus, affirming migration as a human reality as opposed to it being a reality of a given section of humanity. Migration is part of what it means to be human. Its form constantly changes, but its essence, which is humanity, endures. 


\section{References}

Bayles, M. (ed.) (1968). Contemporary Consequentialism, Garden City, NY; Doubleday.

Brook, R. (2007). "Deontology, Paradox, and Moral Evil,” Social Theory and Practice, 33(3): 431-40.

Char, the No-Man's Land (dir. Sourav Sarangi, 2013)

Darwall, S. (ed.) (2003). Consequentialism, Oxford: Blackwell.

Du Bois, W. E. B. (1989). The Souls of Black Folk. New York: Bantam.

García-Peña, L. (2016). The Borders of Dominicanidad: Race, Nation and Archives of Contradiction. Durham: Duke University Press.

Glaser, L. B. (2017). "International Collaboration Results in Play about Borders." Cornell Chronicle. http://www.news.cornell.edu/stories/2017/02/international-collaboration-results-play-about-borders. February 20.

Messkoub, M. (2009). “Migration in a Globalizing World.” Development Issues. 11(2):1-28.

Moore, M. (2008). "Patrolling the Borders of Consequentialist Justifications: The Scope onf Agent-Relative Obligations," Law and Philosophy, 27(1): 35-96.

Mulgan, T. (2001). The Demands of Consequentialism, Oxford: Clarendon Press.

Multicultural Resource Center. (2007). http://multiculturalresourcecenter.org/events/2017/3/2/ithaca-kolkatacollaborative-play-about-migration-debuts.

Muñoz, J. E. (2007). “Chico, What Does it Feel Like to Be a Problem?' The Transmission of Brownness”. Juan Flores and Renato Rosaldo (Eds.) A Companion to Latina/o Studies. 441-451.

My Name is Khan (dir. Karan Johar, 2010)

Root Map (A collaborative play by Debra Castillo, Debaroti Chakraborty, and Debasish Sen Sharma)

Scheffler, S., (1982). The Rejection of Consequentialism, Oxford: Oxford University Press.

The Backyard/ El Traspatio (dir. Carlos Carrera, 2009) 